\title{
AN EXPERIMENTAL INVESTIGATION ON THE ANTI- ARRHYTHMIC ACTIVITY OF ANTIEPILEPTIC AGENTS
}

\author{
N. SINGH, J.N. SINHA, S.K. RASTOGI, P.R. DUA* and R.P. KOHLI \\ Department of Pharmacology \& Therapeutics, King George's \\ Medical College, Lacknow-3, India
}

Received for publication June 25, 1971

Several groups of drugs have been shown to possess antiarrhythmic activity. Some of them e.g. quinidine, procainamide, local anaesthetics, $\beta$-receptor blocking agents and diphenylhydantoin etc. have achieved a clinical status as antiarrhythmic drugs. Diphenylhydantoin (dilantin) an anticonvulsant has been successfully employed for the supression of ventricular arrhythmias due to digitalis over dosage (1) and anaesthesia (2). Atrial arrhythmias on the other hand, did not respond to diphenylhydantoin therapy. Other anticonvulsants like trimethadione (Tridione) and paramethadione (Paradione) have not been studied for the antiarrhythmic activity. Though there is enough clinical evidence of cardiac arrhythmias of central origin viz. arrhythmias during hypothalamic operation (3) electroconvulsive therapy (4) and second stage of anacsthesia, yet in the screening of antiarrhythmic activity most of the workers have neglected the arrhythmias of central nervous system origin. We have recently reported that aconitine induced centrogenic arrhythmia is a good model for screening of antiarrhythmic agents (5). Moreover for the screening of antiarrhythmic activity of CNS active agents, it seems logical that one must include some model of centrogenic arrhythmia as well. In the present investigation diphenylhydantoin, trimethadione and paramethadione have been studied against four types of experimental cardiac arrhythmia viz. (I) aconitine induced controgenic ventricular arrhythmias (II) aconitine induced auricular arrhythmias (III) hydrocarbon-epinephrine induced ventricular arrhythmias (IV) and coronary-ligation induced ventricular arrhythmias.

\section{METHODS}

The experiments were carried out on adult mongrel dogs of either sex. The animals were anaesthetized with pentobarbitone sodium ( $30 \mathrm{mg} / \mathrm{kg}$ i.v.) and maintained on positive pressure artificial respiration. The blood pressure was recorded from one of the carotid artery through mercury manometer on the kymograph paper. The electrocardiogram (EKG lead II) was recorded on Sanborn Polygraph (Model 150). The drugs were administered intravenously through an indwelling polythene cannula in one of the femoral vein.

1. Aconitine induced centrogenic ventricular arrhythmias

Centrogenic cardiac arrhythmia was induced by injecting aconitine $(20 \mu \mathrm{g})$ into the

*Present address: Central Drug Research Institute, Lucknow-3, India. 
lateral cerebral ventricle of $\operatorname{dog}(5)$. At the above mentioned dose, it induced ventricular extrasystoles and tachycardia in all animals. The infusion of the preventing agent was started at the appearance of extrasystoles.

\section{Aconitine induced atrial arrhythmias}

Atrial fibrillation was induced by the method of Scherf (6). The arrhythmia was produced by injecting $0.05 \mathrm{ml}$ of 0.05 percent freshly prepared solution of aconitine in the region of the head of the sinus node in the angle between superior venacava and right atrial appendix. The titration procedure ( 1 or $2 \mathrm{mg} / \mathrm{kg} / \mathrm{min}$ ) of Winbury and Hemmer (7) was followed for the injection of the drugs. The end point taken for complete protection was the restoration of $1: 1$ rhythm with heart rate below 200/min. Before injecting the test drug the arrhythmia was allowed to stabilize at least for 20 minutes in evcry experiment. In control experiments the arrhythmia lasted for more than four hours.

\section{Hydrocarbon-epinephine induced ventricular arrhythmias}

The method of Riker and Wescoe (8) was followed with the modification that all experiments were done in open chest animals to facilitate visual observation. Cardiac arrhythmia was induced in cach animal by the intra-tracheal injection of $0.1 \mathrm{ml} / \mathrm{kg}$ of petroleum ether (B.P. $40-60^{\circ} \mathrm{C}$ ) followed by intravenous injection of $30 \mu \mathrm{g} / \mathrm{kg}$ of epinephrine. Drug was administered intravenously in a single dose prior to administration of petroleum ether and epinephrine. After the administration of lest drug challenging dose of epinephrine was administered at 15, 30, 45 and 60 minutes during petroleum ether inhalation each time. Absence of production of ventricular arrhythmias with the challenging doses of epinephrine during petroleum ether inhalation was taken as protection afforded by the drug. In control experiments the arrhythmias could be induced several times in each case.

\section{Coronary ligation induced ventricular arrhythmias}

Two stage coronary-ligation was done in dogs by the method of Harris and Kokernot (9). Eighteen to twenty four hours after the ligation the animals exhibited ventricular arrhythmias. The preventing agents were given only when the ectopic ventricular extrasystoles or tachycardia appeared.

The drugs employed in the present study were diphenylhydantoin sodium (DilantinParke Davis), trimethadione (Tridione-Abbott), paramethadione (Paradione-Abbott) and quinidine sulphate (Varick). Solution of diphenylhydantoin sodium and quinidine sulphate were made in propylene glycol and the other two drugs were dissolved in normal saline. In control experiments, the effect of propylene glycol was also studied. The preventing agents were given in the form of slow intravenous infusion at the rate of $1 \mathrm{mg}$ or $2 \mathrm{mg} / \mathrm{kg} / \mathrm{min}$ till the heart returned to the normal rhythm.

\section{RESULTS}

\section{Effect of drugs on aconitine induced centrogenic ventricualr arrhythmias}

Effect of three known antiepileptic agents viz. diphenylhydantoin sodium, trimethadione and paramethadione and a known antiarrhythmic agent quinidine was studied on aconitine (I.C.V.) induced centrogenic cardiac arrhythmias in dogs. The results are summarized in 
TABLE 1. Antagonism of centrogenic cardiac arrhythmia induced by I.C.V. administration of $20 \mu \mathrm{g}$ aconitine in dogs.

\begin{tabular}{lcc}
\hline \multicolumn{1}{c}{ Drugs } & $\begin{array}{c}\text { Mean protective dose } \\
\mathrm{mg} / \mathrm{kg} \text { i.v. } \pm \text { S.E. }\end{array}$ & Duration in min \pm S.E. \\
\hline $\begin{array}{l}\text { Quinidine } \\
\text { Diphenylhydantoin sodium }\end{array}$ & $14.5 \pm 0.5$ & $25 \pm 3.2$ \\
Trimethadione* & $12.0 \pm 0.5$ & $15 \pm 2.1$ \\
Paramethadione* $^{*}$ & - & - \\
\hline
\end{tabular}

* Doses up to $50 \mathrm{mg} / \mathrm{kg}$ did not protect but reduced the incidence of ventricular extrasystoles.

CONTROL

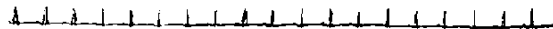

$10 \mathrm{MIN}$

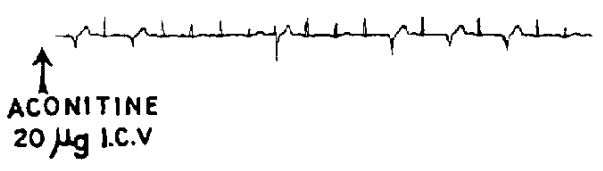

30 MIN

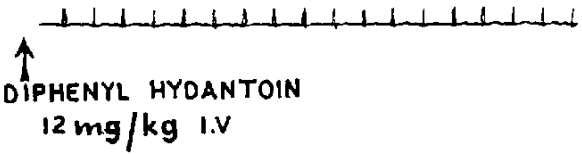

40 MIN

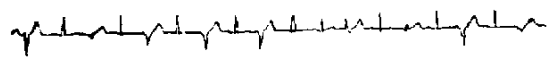

I SEC

Fiv. 1. Shows the effect of diphenylhydantoin (Dilantin) on the centrogenic cardiac arrhythmia induced by aconitine in dog. Upper panel-Control e.k.g. Middle-upper panel shows typical arrhythmias after I.C.V. aconitine. Middle lower panel-12 $\mathrm{mg} / \mathrm{kg}$ i.v. of diphenylhydantoin had reversed the arrhythmias to normal sinus rhythm. Lower panel-note that arrhythmias have reappeared after about 20 minutes.

\section{CONTROA}

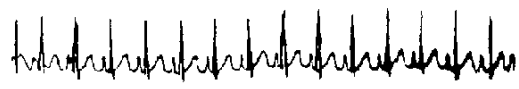


Table 1. Amongst the drugs studied only quinidine and diphenylhydantoin could antagonize the cardiac irregularities. Diphenylhydantoin was found to be more potent (mean protective dose $-12.0 \pm 0.5 \mathrm{mg} / \mathrm{kg}$ i.v.) than quinidine (mean protective dose-14.5 $\_0.50 \mathrm{mg}$ / kg i.v.). Fig. 1 shows the records of one typical experiment with diphenylhydantoin. Trimethadione and paramethadione could not completely antagonize the cardiac irregularities even upto $50 \mathrm{mg} / \mathrm{kg}$ i.v. doses. However, in the higher doses these agents reduced the incidence of ectopic beats (Fig. 2). The duration of antiarrhythmic effect of quindine was found to be 25 minutes as compared to 15 minutes of diphenyl hydantoin.

\section{Effect of drugs on aconitine induced atrial arrhythmias}

Among the antiepileptic drugs tested against aconitine induced atrial fibrillation, only diphenylhydantoin sodium showed antiarrhythmic activity, the other two drugs trimethadione and paramethadione were found to be ineffective. The results of the study are summarized in (Table 2). Diphenylhydantoin sodium in dose of $(30 \mathrm{mg} / \mathrm{kg}$, i.v.) completely reversed the atrial fibrillation to normal rhythm and rate (below $200 / \mathrm{min}$ ). The average duration of effect was 35 minutes.

As regards relative potency, diphenylhydantoin sodium was only half as potent as quinidine in these experiments. However, the duration of action of diphenylhydantoin was more than that of quinidine.

TABLE 2. Effect of diphenylhydantoin, paramethadione and trimethadione against aconitine induced atrial fibrillation in dogs.

\begin{tabular}{lcccc}
\hline \multicolumn{1}{c}{ Drugs } & $\begin{array}{c}\text { No. of } \\
\text { reversions } \\
\text { No. of } \\
\text { experiments }\end{array}$ & $\begin{array}{c}\text { Average dose } \\
\text { producing } \\
\text { reversion } \\
\text { mg/kg } \pm \text { S.E. }\end{array}$ & $\begin{array}{c}\text { Duration of } \\
\text { cffect in } \\
\text { min }\end{array}$ & Remarks \\
Quinidine & $7 / 8$ & $16.2 \pm 3.4$ & $20 \pm 3.2$ & $\begin{array}{c}\text { Reversion to } \\
\text { normal rhythm }\end{array}$ \\
Diphenylhydantoin sodium & $6 / 8$ & $30.0 \pm 2.8$ & $35 \pm 2.2$ & No reversion \\
$\begin{array}{l}\text { Paramethadione } \\
\text { Trimethadione }\end{array}$ & $0 / 4$ & $50.0 \pm 0.0$ & - & \\
\hline
\end{tabular}

3. Preventive action of drugs on the hydrocarbon-epinephrine induced ventricular arrhythmias

The ability of diphenylhydantoin sodium, paramethadione, trimethadione and quinidine to prevent hydrocarbon-cpinephrine induced ventricular arrhythmia was studied in 25 dogs of both sexes. Ventricular arrhythmias could be produced every time in all the control experiments when epinephrine was administered during petroleum ether inhalation. The onset of arrhythmia was, at 1 to 2 minules and it lasted for 3 to 5 minutes each time. It could be repeatedly produced at least five times in control experiments. However, the dogs in whom the effect of drugs were studied, the first challenge with petroleum ether and epincphrine was taken as a control for that experiment. The results of the present study are summarized in (Table 3). Diphenylhydantoin sodium in single dose of $10 \mathrm{mg} / \mathrm{kg}$ and quinidine $5 \mathrm{mg} / \mathrm{kg}$ showed 90 and 100 percent prevention of ventricular arrhythmias respectively, while paramethadione and trimethadione were ineffective even upto $50 \mathrm{mg} / \mathrm{kg}$ doses (Table 3). Typical ventricular arrhythmias induced with epinephrine during petroleum 
TABLE 3. Prevention of hydrocarbon-epinephrine induced arrhythmias in dogs by drugs.

\begin{tabular}{lccccc}
\hline \multicolumn{1}{c}{ Drugs } & $\begin{array}{c}\text { Dose } \\
\text { mg } \mathrm{kg}\end{array}$ & $\begin{array}{c}\text { No. of } \\
\text { animals }\end{array}$ & $\begin{array}{c}\text { No. of } \\
\text { challanges made } \\
\text { with petroleum } \\
\text { ether and } \\
\text { epinephrine }\end{array}$ & $\begin{array}{c}\text { No. of } \\
\text { challanges } \\
\text { exhibiting } \\
\text { ventricular } \\
\text { arrhythmia after } \\
\text { drug treatment }\end{array}$ & $\begin{array}{c}\text { Percent } \\
\text { prevention }\end{array}$ \\
\hline Control & - & $7(2)^{*}$ & 22 & 22 & - \\
Quinidine & 5 & 5 & 20 & 0 & 100 \\
$\begin{array}{l}\text { Diphenylhydantoin sodium } \\
\text { Trimethadione }\end{array}$ & 10 & 5 & 20 & 2 & 90 \\
Paramethadione & 50 & $4(1)^{*}$ & 9 & 9 & 0 \\
\hline
\end{tabular}

* Dogs died due to ventricular fibrillation

CONTAOL

CONTRO
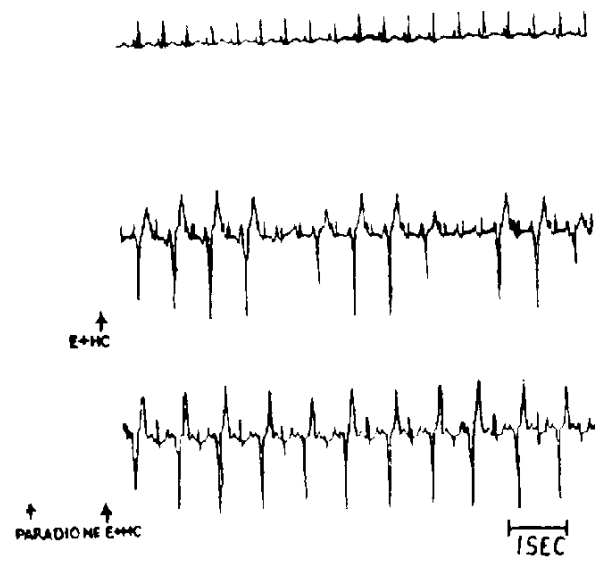

Fic. 3. Shows the effect of paramethodione on hydrocarbon-cpinephrine induced arrhythmias in dogs. Upper panel-control (Normal) e.k.g. Middle panel-control arrhythmias induced by cpinephrine and petroleum ether $(\mathrm{H}+\mathbf{H C})$. In the lower pancl at arrow paradione $50 \mathrm{mg} \mathrm{kg}$ i.v. was given. At $(\mathrm{E} \perp \mathrm{HC})$ challenging dose of epinephrine and petroleum ether was given. Note that paradione could not prevent the occurence of the arrhythmias.

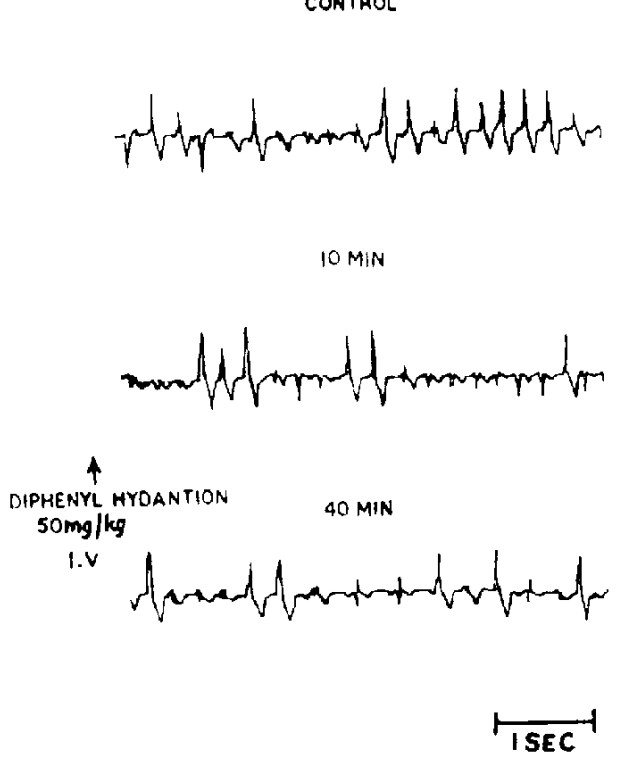

Fig. 4. Shows effect of diphenylhydantoin (Dilantin) on the coronary-ligation arrhythmias in dogs. Upper panel-control arrhythmias after coronary ligation. Middle panel-at arrow diphenylhydantoin $50 \mathrm{mg} / \mathrm{kg}$ given i.v. has shown some protection as the irregularitics are diminished. This effect, though partial, could be observed even after 40 minutes of the drug administration (lower panel).

ether and the effect of paramethadione (Paradione) on the development of arrhythmias are shown in Fig. 3.

\section{Effect of drugs on coronary-ligation induced ventricular arrhythmias}

In another series of experiments cardiac arrhythmias were induced by two stage coronaryligation and the effect of three antiepileptic agents and quinidine was studied. Amongst the drugs studied only quinidine could effectively antagonize the cardiac irregularities (mean 
TABLE 4. Antagonism of coronary-ligation arrhythmias in dogs.

\begin{tabular}{lcc}
\multicolumn{1}{c}{ Drugs } & $\begin{array}{c}\text { Mean protective dose } \\
\mathrm{mg} / \mathrm{kg} \text { i.v. } \pm \text { S.E. }\end{array}$ & $\begin{array}{c}\text { Duration in } \\
\text { min } \pm \text { S.E. }\end{array}$ \\
$\begin{array}{l}\text { Quinidine } \\
\text { Diphenylhydantoin sodium* }\end{array}$ & $12.5 \pm 0.5$ & $2.8 \pm 3.5$ \\
Trimethadione* & - & - \\
Paramethadione* & - & - \\
\hline * Doses upto $50 \mathrm{mg} / \mathrm{kg}$ did not protect but reduced the incidence of \\
ventricular extrasystoles.
\end{tabular}

protective dose $=12.5 \pm 0.50 \mathrm{mg} / \mathrm{kg} \mathrm{i.v.}$ ). None of the antiepileptic agents could completely antagonize the coronary-ligation induced ventricular arrhythmias even upto $50 \mathrm{mg} / \mathrm{kg}$ i.v. doses. However, higher doses of these agents could definitely reduce the incidence of the ectopic beats (Fig. 4). The results are summarized in Table 4.

\section{DISCUSSION}

The results of the present investigation clearly show that diphenylhydantoin antagonizes hydrocarbon-epinephrine induced and aconitine induced centrogenic cardiac arrhythmias in 10.0 and $12.0 \mathrm{mg} / \mathrm{kg}$ respectively. On the other hand, very high doses of the drug is required to prevent or reduce the aconitine induced auricular and coronary ligation induced ventricular arrhythmias. Mendez and Kabella (12) used diphenylhydantoin with success in the cases of ventricular arrhythmia during anaesthesia which is known to be due to catecholamines. However, the drug did not prove beneficial in the cases of atrial flutter and fibrillation. The failure of the drug in clinical atrial arrhythmias seem to be due to the fact that it is not possible to employ such high doses $(30 \mathrm{mg} / \mathrm{kg}$ i.v.).

Both trimethadione and paramethadione in contrast to diphyenylhydantoin were found ineffective against all three types of peripheral arrhythmias (aconitine induced auricular, hydrocarbon-epinephrine and coronary-ligation ventricular arrhythmias). These agents also could not block the aconitine induced centrogenic arrhythmias but reduced the incidence of ectopic beats.

It is obvious from the results that diphenylhydantoin is effective against all types of arrhythmias irrespective of the nature and site of their origin. Such an action can only be due to a nonspecific membrane stabilizing action of the agent. The stabilizing action of diphenylhydantoin against potentiation by repetetive stimuli has been shown on all excitable membranes (10). Moreover, the drug is effective against hyperexcitability of nerve fibres due to low calcium concentration. The above hypothesis is further substantiated by the fact that other antiepileptics viz. trimethadione and paramethadione which appear to be devoid of membrane stabilizing activity as they fail to protect the peripheral nerves against excitatory effects of excessive stimulation or calcium deficit (1), are not effective against aconitine induced auricular, hydrocarbon-epinephrine and coronary-ligation induced ventricular arrhythmias. The results of our study also point to the absence of membrane stabilizing activity in trimethadione and paramethadione since they were only effective against centrogenic arrhythmias. The observation that trimethadione and paramethadione reduced 
the incidence of aconitine induced centrogenic arrhythmia seems logical because these agants are known to depress the transmission at synapses in the central nervous system (11).

\section{SUMMARY}

Antiarrhythmic activity profile of some antiepileptic agents (diphenylhydantoin, paramethadione and trimethadione) has been investigated in the present work. Emphasis has been specially laid for their effect on aconitine induced arrhythmia of central origin. Diphenylhydantoin (Dilantin) showed protection against central (I.C.V. aconitine induced) and peripheral (aconitine induced auricular, hydrocarbon-epinephrine and coronary-ligation induced) arrhythmias. In contrast to diphenylhydantoin, the other antiepileptics-trimethadione and paramethadione were found ineffective against peripheral arrhythmias. However, they showed some protection against the arrhythmia of central origin. Diphenylhydantoin possibly because of its nonspecific membrane stablizing nature was effective against all types of arrhythmias irrespective of the nature and site of their origin; while trimethadione and paramethadione were ineffective against all peripheral arrhythmias and showed some protection against arrhythmias of central origin. The effect of the latter two drugs on central arrhythmias may be altributed to their depressant effect at the synaptic transmission in the central nervous system.

\section{REFERENCES}

1) Toman, J.E.P.: Drags Effective in Convalsive Disorders, The Pharmacological Basis of Therapeutics, Edited by Goodman, L.S. And Gilman, A., p. 204, The Macmillan Co., New York (1970)

2) Mendez, R. and Kabfi.A, E.: Ann. Rev. Pharmac. 10, 291 (1970)

3) POOL, J.L. AND Kessler, L.A.: .J. Ncurosurg. 15, 52 (1958)

4) Usubtaga, J.E., Gustafron, W., Moya, F. and Goldstern, B.: Br. J. Anaesth. 39, 857 (1967)

5) Sinha, J.N., Silams 1 , M.A., Kohlt, R.P. and Bhargava, K.P.: Jap. J. Pharmac. (1971) (In press)

6) SCHERf, D.: Proc. Soc. exp. Biol. Med. 64, 333 (1947)

7) Winbury, M.M. and Hemmer, M.L.: J. Pharmac. exp. Ther. 113, 402 (1955)

8) Rikf.r, W. F. ANd Wescol, W.C.: Ann. N. Y. Acad. Sci. 54, 373 (1951)

9) Harris, A.S. and Kokernot, R.H.: Am. J. Physiol. 163, 505 (1950)

10) Toman, J.E.P.: Pharmac. Rey. 4, 168 (1952)

11) Esplin, D.W. and Curto, E.M.: J. Pharmac. exp. Ther. 121, 457 (1957) 